\title{
Effects of Tianeptine on Onset Time of Pentylenetetrazole-Induced Seizures in Mice: Possible Role of Adenosine A, Receptors
}

\author{
Tayfun I Uzbay*,', Hakan Kayir' and Mert Ceyhan' \\ 'Department of Medical Pharmacology, Psychopharmacology Research Unit, Gulhane Military Medical Academy, Ankara, Turkey
}

\begin{abstract}
Depression is a common psychiatric problem in epileptic patients. Thus, it is important that an antidepressant agent has anticonvulsant activity. This study was organized to investigate the effects of tianeptine, an atypical antidepressant, on pentylenetetrazole (PTZ)-induced seizure in mice. A possible contribution of adenosine receptors was also evaluated. Adult male Swiss-Webster mice (25-35 g) were subjects. PTZ (80 mg/kg, i.p.) was injected to mice $30 \mathrm{~min}$ after tianeptine $(2.5-80 \mathrm{mg} / \mathrm{kg}$, i.p.) or saline administration. The onset times of 'first myoclonic jerk' (FMJ) and 'generalized clonic seizures' (GCS) were recorded. Duration of $600 \mathrm{~s}$ was taken as a cutoff time in calculation of the onset time of the seizures. To evaluate the contribution of adenosine receptors in the effect of tianeptine, a nonspecific adenosine receptor antagonist caffeine, a specific $A_{1}$ receptor antagonist 8-cyclopentyl-I,3-dipropylxanthine (DPCPX), a specific A2 receptor antagonist 8-(3-chlorostyryl) caffeine (CSC) or their vehicles were administered to the mice 15 min before tianeptine $(80 \mathrm{mg} / \mathrm{kg})$ or saline treatments. Tianeptine (40 and $80 \mathrm{mg} / \mathrm{kg}$ ) pretreatment significantly delayed the onset time of FMJ and GCS. Caffeine ( $10-60 \mathrm{mg} / \mathrm{kg}$, i.p.) dose-dependently blocked the retarding effect of tianeptine $(80 \mathrm{mg} / \mathrm{kg}$ ) on the onset times of FMJ and GCS. DPCPX $(20 \mathrm{mg} / \mathrm{kg})$ but not CSC $(1-8 \mathrm{mg} / \mathrm{kg})$ blocked the effect of tianeptine $(80 \mathrm{mg} / \mathrm{kg})$ on FMJ. Our results suggest that tianeptine delayed the onset time of PTZ-induced seizures via adenosine $A_{1}$ receptors in mice. Thus, this drug may be a useful choice for epileptic patients with depression.

Neuropsychopharmacology (2007) 32, 4I2-4I6. doi:I0.1038/sj.npp. I 30I I43; published online 28 June 2006
\end{abstract}

Keywords: tianeptine; pentylenetetrazole; adenosinergic receptors; caffeine; DPCPX; CSC

\section{INTRODUCTION}

Depression is a very important problem in epileptic patients (Robertson, 1985). However, many antidepressant drugs, such as selective serotonin reuptake inhibitors (SSRI) and tricyclics may lower the seizure threshold or have proconvulsant activity (Hollister, 1978). Thus, selecting a rational and harmless antidepressant therapy for epileptic patients with depression is very important.

Tianeptine is a tricyclic drug that exhibits antidepressant activity in experimental models and clinical trials. It selectively accelerates presynaptic serotonin reuptake at the synaptic cleft (Mennini et al, 1987; Fattaccini et al, 1990), in contrast to other antidepressant drugs such as SSRIs and tricyclics. Experimental studies have also been showed that tianeptine had some beneficial effects on acute stress-induced structural remodeling in hippocampus

\footnotetext{
*Correspondence: Professor TI Uzbay, Department of Medical Pharmacology, Psychopharmacology Research Unit, Gulhane Military Medical Academy, Etlik, 06018 Ankara, Turkey, Tel: +90312304 4764, Fax: +90312304 2010, E-mail: tuzbay@gata.edu.tr Received 17 February 2006; revised 22 May 2006; accepted 25 May 2006

Online publication: 31 May 2006 at http://www.acnp.org/citations/ Npp053 I06060 I I //default.pdf
}

involving debranching and shortening of dendrites and suppression of neurogenesis (Watanabe et al, 1992; Czéh et al, 2001; Rocher et al, 2004).

Some tianeptine analogous prolonged the onset of the tonic convulsions and death induced by pentylenetetrazole (PTZ) in mice (Sanchez-Mateo et al, 2003). In addition, in a recent study from our laboratory (Ceyhan et al, 2005) indicated that tianeptine but not fluoxetine, an SSRI, have a beneficial inhibitory effect on PTZ-induced seizures in rats. In another study from our laboratory indicated that tianeptine has an inhibitory effect on audiogenic seizure in ethanol-withdrawn rats (Uzbay et al, 2006). Although these findings imply that tianeptine could have anticonvulsant activity, the mechanism of the anticonvulsant effect of tianeptine was not clarified in these studies. However, in a recent preliminary study, we obtained some indications implying that adenosinergic system may have a role in the effects of tianeptine on PTZ-induced seizures (Uzbay et al, 2004).

Adenosine functions as a neuromodulator and presynaptically inhibits the release of many neurotransmitters. It also reduces the rate of spontaneous firing of many neurons in the brain and produces a basal adenosinergic tonus, which has inhibitory effects in general (Fredholm, 1995; McKim, 2000). Adenosine acts through specific G-protein coupled 
receptors and activates $A_{1}$ and $A_{2 A}$ subtypes of adenosinergic receptors at physiological concentrations. Thus, it can be concluded that $A_{1}$ and $A_{2 A}$ receptors are responsible for the basal inhibitory adenosinergic tonus (Snyder, 1981; Williams, 1990; Fredholm et al, 2001). Besides having a role in many inhibitory central mechanisms, adenosine has also been implicated in arrest of seizures. The anticonvulsant action of adenosine and its analogues has been showed both in vivo (Maitre et al, 1974; Petersen, 1991) and in vitro (Dunwiddie, 1980) studies on rodents. In addition, it has been observed that the levels of endogenous adenosine were dramatically elevated in the brain following seizures (Chin, 1989).

The present study was organized to investigate the effects of tianeptine on PTZ-induced seizures in mice. Then, we aimed to evaluate a possible contribution of adenosine receptors to beneficial effect of tianeptine on PTZ-induced seizures in mice. Thus, we used caffeine, a nonselective blocker of adenosine receptors (Snyder, 1981), 8-cyclopentyl-1,3-dipropylxanthine (DPCPX), a selective blocker of $\mathrm{A}_{1}$ receptors (De Sarro et al, 1999), and 8-(3-chlorostyryl) caffeine (CSC), a selective blocker of $A_{2 A}$ receptors for testing a possible relationship between the inhibitory effects of tianeptine on the seizures and adenosinergic receptors.

\section{MATERIALS AND METHODS}

\section{Animals and Laboratory}

Adult female Swiss-Webster mice (25-35 g) were subjects in the present study. They were housed in a quiet and temperature-and humidity-controlled room $\left(22 \pm 2{ }^{\circ} \mathrm{C}\right.$ and $60 \pm 5 \%$, respectively) in which a 12 -h (light/dark) cycle was maintained (07:00-19:00 light). All experiments were performed at the same time of the day and in the light period (09:00-11:30).

All procedures in the present study are in accordance with the Guide for the Care and Use of Laboratory Animals as adopted by the National Institutes of Health (Washington, DC, USA, 1996). All efforts were made to minimize animal suffering to reduce the number of animals used. The animals were controlled for their pregnancy status. We made sure that the mice selected for the study were not pregnant.

\section{Drugs}

Caffeine PTZ, DPCPX and CSC were purchased from Sigma Chemical (USA). Tianeptine was a generous gift from Servier (TR). Caffeine, PTZ and tianeptine were dissolved in $0.9 \%$ saline. DPCPX was dissolved in dimethyl sulphoxide (DMSO, Sigma Chemical, USA) and sodium hydroxide $(\mathrm{NaOH}, 0.1 \mathrm{M})$, and diluted with saline. The final concentrations at the highest dose were 15 and $8 \%(\mathrm{v} / \mathrm{v})$ for DMSO and $\mathrm{NaOH}$, respectively. CSC was also dissolved in DMSO and diluted with saline. The final concentration of DMSO was $15 \%(\mathrm{v} / \mathrm{v})$ at the highest dose. All drugs injected intraperitoneally in a volume of $10 \mathrm{ml} / \mathrm{kg}$. Drug solutions were prepared freshly in the morning.

\section{Experimental Procedures}

Mice were assigned into individual groups randomly. Each group had eight animals in the present study. All animals were handled and habituated to the locomotor activity cages before the tests.

To understand which doses of tianeptine are sedative and/or muscle relaxant, we performed the locomotor activity measurments first. Tianeptine $(10-160 \mathrm{mg} / \mathrm{kg})$ was administered to the mice and the effects on locomotor activity were evaluated for $30 \mathrm{~min}$ by an open-field activity monitoring system (MAY 9908 model-Activity Monitoring System-Commat Ltd., TR). Locomotor activity was recorded as a total of horizontal, vertical and ambulatory activities of the mice. Maximum dose of tianeptine, which did not affect the locomotor activity, was selected as $80 \mathrm{mg} /$ $\mathrm{kg}$. Tianeptine was injected to mice $30 \mathrm{~min}$ before the tests.

In subsequent experiments, tianeptine $(2.5-80 \mathrm{mg} / \mathrm{kg}$, i.p.) or saline was administered to mice $30 \mathrm{~min}$ prior to PTZ (80 mg/kg, i.p.) injection. Immediately after PTZ treatment, mice were placed in a Plexiglas cage and observed for onset times of 'first myoclonic jerk' (FMJ) and 'generalized clonic seizures' (GCS) as previously described (Kaputlu and Uzbay, 1997). The onset times were recorded as seconds. The observation period for PTZ-induced seizures were limited to $30 \mathrm{~min}$. Duration of $600 \mathrm{~s}$ was taken as a cutoff time in calculation of the onset time of PTZ-induced seizures. As FMJ and GCS indicate initiation and spreading of the seizures, respectively, we tested and evaluated both parameters involved in the PTZ-induced seizures in the present study.

To evaluate the contribution of adenosine receptors in the effect of tianeptine, a nonspecific adenosine receptor antagonist caffeine, a specific $A_{1}$ receptor antagonist DPCPX and a specific $A_{2 A}$ receptor antagonist CSC or their vehicles administered to the mice $15 \mathrm{~min}$ before tianeptine $(80 \mathrm{mg} / \mathrm{kg})$ or saline treatments.

\section{Statistics}

The effects of tianeptine on locomotor activity and seizures were evaluated by one-way analysis of variance (ANOVA) test followed by Dunnett's test for post hoc comparisons. In addition, the effects of various doses of caffeine and CSC on the anticonvulsant effect of tianeptine $(80 \mathrm{mg} / \mathrm{kg})$ were also evaluated by the same statistical protocol. Student's $t$-test was used in comparing saline or vehicle groups with tianeptine $(80 \mathrm{mg} / \mathrm{kg})$ group. Student's $t$-test was also used to evaluate the effects of DPCPX. The level of statistical significance was set at $p<0.05$.

\section{RESULTS}

Tianeptine, at the dose of $160 \mathrm{mg} / \mathrm{kg}$, significantly depressed the locomotor activity of mice $[\mathrm{F}(5,42)=5.695 ; p<0.0001]$ (Figure 1). Thus, tianeptine doses selected for the further experiments were lower than $160 \mathrm{mg} / \mathrm{kg}$ (ie 40 and $80 \mathrm{mg} / \mathrm{kg}$ ).

Tianeptine pretreatment significantly delayed the FMJ and GCS onset times at the doses of 40 and $80 \mathrm{mg} / \mathrm{kg}$ $[\mathrm{F}(6,74)=16.975 ; p<0.0001]$ (Figure 2a and b), while delayed only the GCS onset time, at the dose of $80 \mathrm{mg} / \mathrm{kg}$ $[\mathrm{F}(6,69)=9.551 ; p<0.0001]$ (Figure 2b).

Caffeine $(10-60 \mathrm{mg} / \mathrm{kg})$ alone, did not affect the onset times of FMJ and GCS $[F(4,35)=0.603$ and 0.563 , for FMJ and GCS respectively; $p$-values $>0.05$ ] (Data not shown).

Caffeine (10-60 mg/kg, i.p.) dose-dependently blocked the delaying effect of tianeptine $(80 \mathrm{mg} / \mathrm{kg})$ on the onset times 


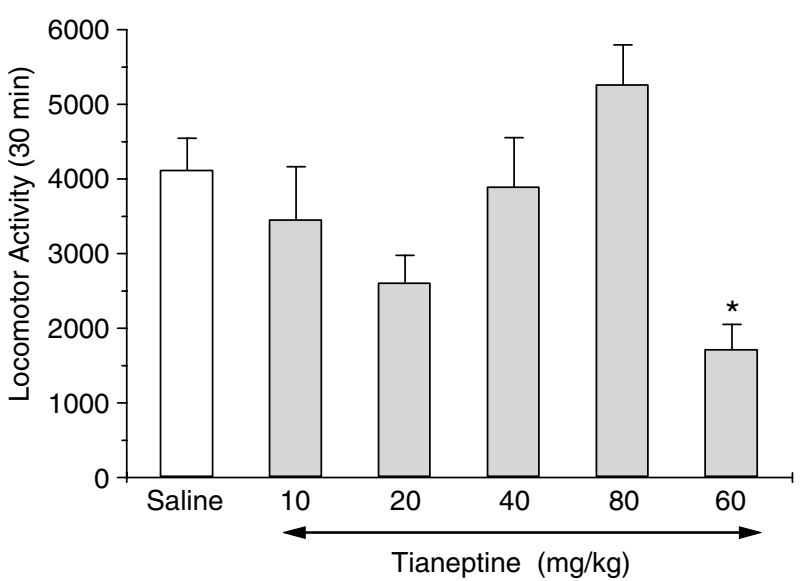

Figure I Effect of tianeptine on locomotor activity of mice ( $n=8$ for each group; $*=0.009$, Dunnett's test).
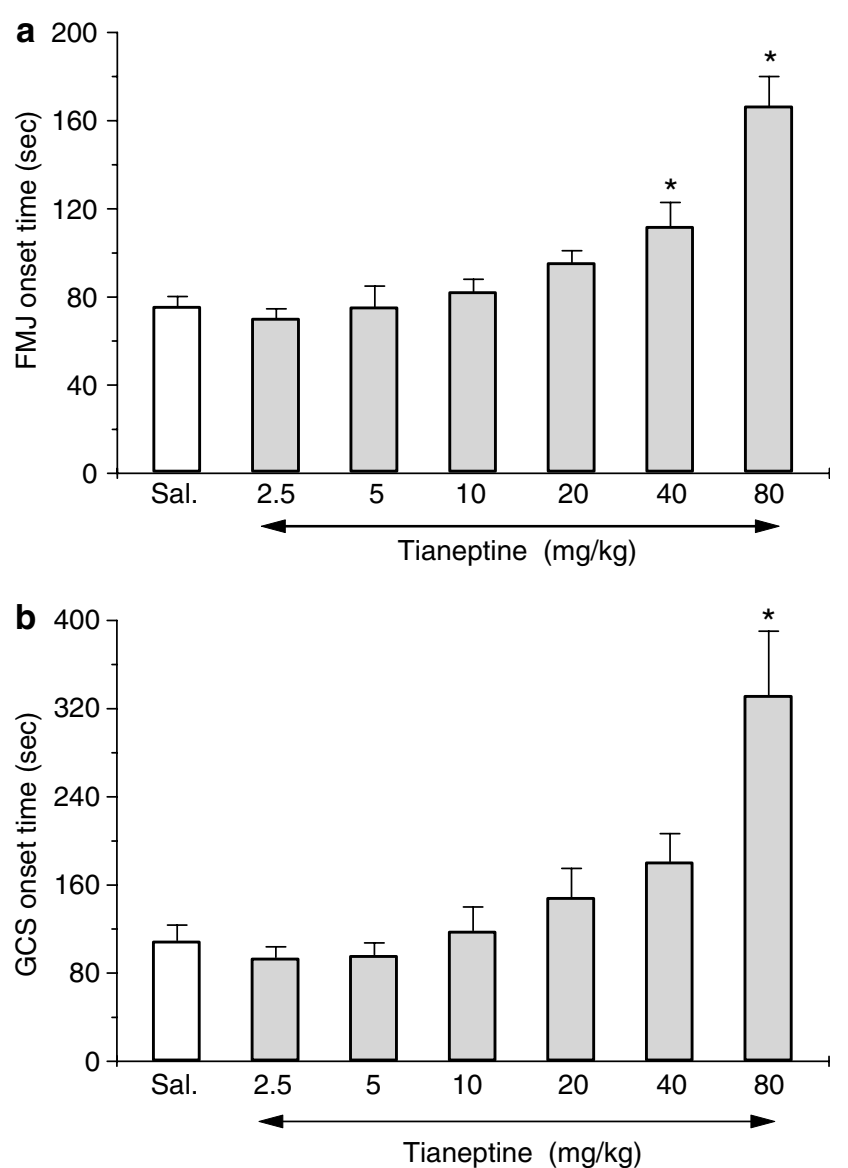

Figure 2 Effects of tianeptine on the onset times of 'first myoclonic jerk' (FMJ) (a), and 'generalised clonic seizures' (GCS) (b) produced by pentylenetetrazole in mice $(* p<0.05$, Dunnett's test; Sal. = Saline control).

of FMJ (Figure 3a) and GCS (Figure 3b) $[\mathrm{F}(4,35=10.023$ $p<0.0001 \& \mathrm{~F}(4,33)=7.628 ; p=<0.0001$, respectively].

DPCPX $(1.25-20 \mathrm{mg} / \mathrm{kg})$ alone, did not affect the FMJ onset time $[\mathrm{F}(5,36)=2.469 ; p>0.05]$, while reduced the GCS onset time $[\mathrm{F}(5,36)=3.544 ; p=0.01]$ in PTZ administered mice (data not shown).

DPCPX pretreatment, at the ineffective dose on the FMJ onset time $(20 \mathrm{mg} / \mathrm{kg})$, blocked the delaying effect of
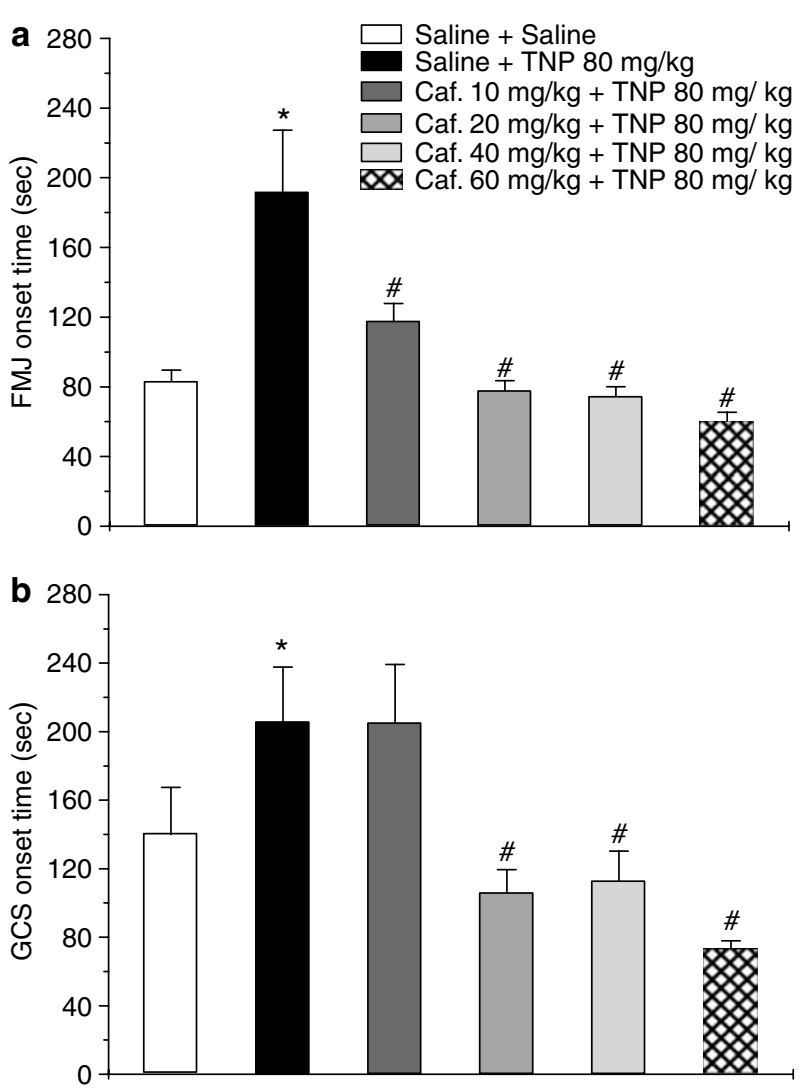

Figure 3 Blocking effect of caffeine on the effects of tianeptine (TNP) on the onset times of 'first myoclonic jerk' (FMJ) (a), and 'generalised clonic seizures' (GCS) (b) produced by pentylenetetrazole (PTZ) (Caf.: Caffeine; $* p<0.05$, Student's $t$-test, significantly different from the 'Saline + Saline' group; ${ }^{\#} p<0.05$, Dunnett's test, significantly different from the 'Saline + TNP $80 \mathrm{mg} / \mathrm{kg}^{\prime}$ group).

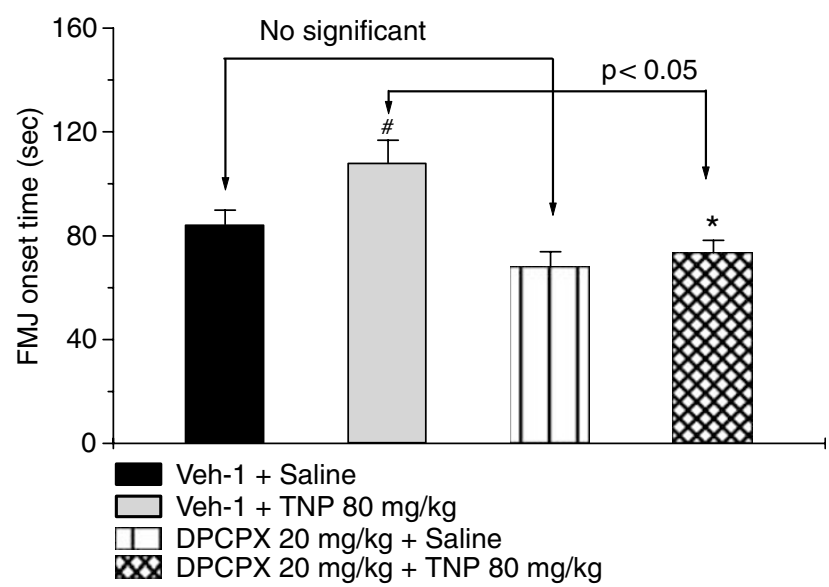

Figure 4 Blocking effect of DPCPX on the effects of tianeptine (TNP) on the onset time of 'first myoclonic jerk' (FMJ) produced by PTZ (Veh- I: Vehicle-I =DMSO I5\% + NaOH 8\% (0.I M); PTZ: pentylenetetrazole; DPCPX: 1,3-dipropyl-8-cyclopentylxanthine; $* p<0.05$, Student's $t$-test, significantly different from the 'Veh-I + TNP $80 \mathrm{mg} / \mathrm{kg}^{\prime}$ group; ${ }^{*} p<0.05$, Student's $t$-test, significantly different from the 'Veh-I + saline' group).

tianeptine $(80 \mathrm{mg} / \mathrm{kg})$ on this variable $(p<0.05$, Student's $t$-test) (Figure 4).

CSC alone delayed the FMJ onset time in PTZ administered mice $[\mathrm{F}(4,31)=2.847 ; p=0.040]$. Post hoc Dunnett's 


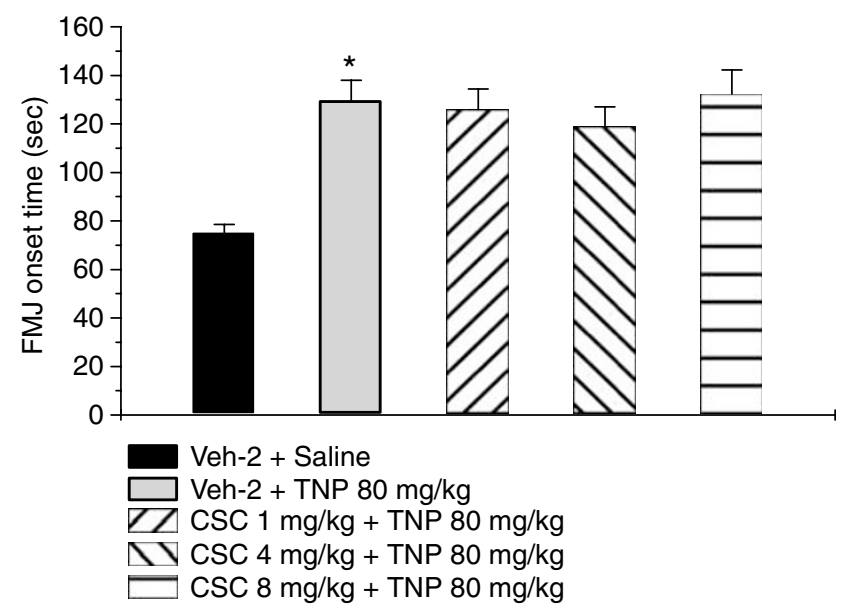

Figure $5 \mathrm{CSC}$ pretreatment did not change the effect of tianeptine (TNP) on the onset time of 'first myoclonic jerk' (FMJ) produced by PTZ (Veh-2: Vehicle-2=DMSO 15\%; PTZ: pentylenetetrazole; CSC: 8-(3-chlorostyryl) caffeine; $* 0<0.05$, Student's $t$-test, significantly different from the 'Veh-2 + TNP $80 \mathrm{mg} / \mathrm{kg}$ ' group).

tests revealed a significant inhibitory effect at dose of $16 \mathrm{mg} / \mathrm{kg}(p=0.025)$ but not at 1,4 and $8 \mathrm{mg} / \mathrm{kg}$ doses $(p=0.998, p=0.998$ and $p=0.969$, respectively) (data not shown).

CSC $(1-8 \mathrm{mg} / \mathrm{kg})$ pretreatment did not change the effect of tianeptine $(80 \mathrm{mg} / \mathrm{kg})$ on FMJ onset time $[\mathrm{F}(3,28)=0.436$; $p=0.729]$ (Figure 5).

Tianeptine was not found effective on mortality of the PTZ-induced seizures in the present study (data not shown).

\section{DISCUSSION}

Our results suggest that tianeptine delayed significantly and dose-dependently the onset time of PTZ-induced FMJ and GCS in mice. In addition, the effect of tianeptine on seizures was blocked by caffeine, a nonspecific antagonist of adenosinergic receptors and DPCPX, a selective adenosine $\mathrm{A}_{1}$ receptor antagonist, but not $\mathrm{CSC}$, a selective $\mathrm{A}_{2 \mathrm{~A}}$ antagonist pretreatment. Furthermore, because tianeptine did not change the locomotor activity at effective doses on the seizure, our findings imply that tianeptine acts through its effect on central nervous system, rather than some nonspecific actions such as sedation or muscle relaxation. Overall the data indicate that tianeptine may have an anticonvulsant activity via adenosinergic $A_{1}$ receptors in mice. As all animals died after tianeptine treatment like those in controls, we could not evaluate severity of the seizures. According to our results, it seems to be that tianeptine produced some beneficial effects on initiation rather than spreading of PTZ-induced seizures.

In the present study, doses of tianeptine were selected according to our preliminary experiments. Previous studies performed in rodents indicated that tianeptine was effective at lower doses as compared with those using in the present study. For example, it had an anticonvulsant activity in rats at dose of $10 \mathrm{mg} / \mathrm{kg}$ (Ceyhan et al, 2005). In contrast to rats, we did not observe any significant effect on PTZ-induced seizures by tianeptine treatment in mice up to dose of $40 \mathrm{mg} / \mathrm{kg}$. This situation may be related to different pharmacokinetic profiles of tianeptine in mice and rats. In a previous study from our laboratory, although we found analgesic activity in mice by a lower dose of tianeptine (Uzbay et al, 1999), seizures and nociception are different events. Higher doses may be necessary for controlling the seizures. The effective doses of tianeptine used in the present study did also not cause any significant impairment on motor activity in mice. This observation implies, at least, that selected doses for tianeptine and combination studies were not neurotoxic.

Our findings on the delaying effects of tianeptine on PTZinduced seizures support the results of Ceyhan et al (2005) who observed that tianeptine inhibited PTZ-induced seizures in rats. In the present study, we have confirmed those results with tianeptine in mice and extended those results by using adenosine receptor antagonists. These results may be important because this is the first data indicating an interaction between tianeptine and adenosinergic receptors. Previous studies on binding potential of tianeptine to any of the receptors indicated that this drug does not bind to $5-\mathrm{HT}_{1 \mathrm{~A}}, 5-\mathrm{HT}_{1 \mathrm{~B}}, 5-\mathrm{HT}_{2}$ and presynaptic 5 -HT receptors, $\beta$-adrenoceptors, dopamine $\mathrm{D}_{2}$ receptors, GABA, glutamate, benzodiazepine, muscarinic and histamine receptors, imipramine binding sites or calcium channels (Mennini et al, 1987; Kato and Weitsch, 1988; Ansseau, 1993).

Adenosine has been implicated in the spontaneous and abrupt arrest of seizures. The anticonvulsant effect of adenosine has been observed in various studies. In in vitro studies, adenosine depresses seizure activity in hippocampal slices (Dunwiddie, 1980). While in rodents, adenosine and its analogues protect against audiogenic (Maitre et al, 1974), chemically induced (Marangos et al, 1990; Petersen, 1991) and kindled seizures (Dragunow and Goddard, 1984). Rapid elevations in brain levels of adenosine have also been reported after experimental seizures (Schultz and Lowenstein, 1978; Winn et al, 1980) and postseizures in epileptic patients (During and Spencer, 1992).

Adenosine stimulates two major receptor subtypes $A_{1}$ and $A_{2 A}$, which are linked to multitude of effectors namely, adenylate cyclase, inositol phosphate, potassium channels, calcium channels, and neurotransmitter release (Williams, 1990). Malhotra and Gupta (1997) suggested that adenosine mediated anticonvulsant effect on PTZ-induced seizures via stimulation of $A_{1}$ receptors in rats. In addition, numerous data show that adenosine $A_{1}$ receptor density is enhanced in specific brain regions following PTZ-induced seizures (Angelatou et al, 1990; Pagonopoulou et al, 1993; Tchekalarova et al, 2005). De Sarro et al (1999) also demonstrated that stimulation of $A_{1}$ and $A_{2 A}$ receptors plays a role in the inhibition of seizures in audiogenic seizure sensitive mice. These observations clearly indicate that there is a relationship between adenosinergic receptor activation and anticonvulsant activity.

In the present study, we have found that the nonselective $A_{1} / A_{2}$ adenosine receptor antagonist, caffeine and the selective $A_{1}$ receptor antagonist, DPCPX, but not $A_{2 A}$ antagonist, CSC, pretreatment blocked the delaying effects of tianeptine on the onset time of seizures induced by PTZ. This finding implies that tianeptine could produce the anticonvulsant effect via adenosine $A_{1}$ receptors. Furthermore, in contrast to caffeine, DPCPX pretreatment was 
ineffective in blocking the effects of tianeptine on the onset time of GCS. It only blocked the effects of tianeptine on PTZ-induced FMJ in mice. CSC pretreatment also did not blocked the effect of tianeptine on GCS. This observation demonstrated that $A_{1}$ receptors may have a more significant role in tianeptine effects on the onset time of PTZ-induced FMJ. As both caffeine and DPCPX alone were not effective on FMJ and GCS, their blocking effect on tianeptine are specific and not related to their own seizure-inducing effects. However, more clarification of the relationship between adenosinergic receptors and tianeptine by further studies such as receptor binding analysis may be important. This may provide new therapeutic approaches on tianeptine treatments for clinicians.

In conclusion, our results suggest that tianeptine delayed the onset time of PTZ-induced seizures in mice via adenosinergic $A_{1}$ receptors. This drug may be useful for the treatment of epileptic patients with depression.

\section{ACKNOWLEDGEMENTS}

We thank Mr Selami Alan for his technical assistance to the study.

\section{REFERENCES}

Angelatou F, Pagonopoulou G, Kostapoulos G (1990). Alterations of adenosine A1 receptors in different mouse brain areas after pentylenetetrazol-induced seizures but not in the epileptic mutant mouse 'tottering'. Brain Res 534: 251-256.

Ansseau M (1993). The paradox of tianeptine. Eur Psychiatr 8(Suppl 2): S89-S93.

Ceyhan M, Kayir H, Uzbay IT (2005). Investigation of the effects of tianeptine and fluoxetine on pentylenetetrazole-induced seizures in rats. J Psychiatr Res 39: 191-196.

Chin JH (1989). Adenosine receptors in brain: neuromodulation and role in epilepsy. Ann Neurol 26: 695-698.

Czéh B, Michaelis T, Watanabe T, Frahm J, de Biurrun G, van Kampen $M$ et al (2001). Stress-induced changes in cerebral metabolites, hippocampal volume, and cell proliferation are prevented by antidepressant treatment with tianeptine. Proc Natl Acad Sci USA 98: 12320-12322.

De Sarro G, De Sarro A, Di Paola ED, Bertorelli R (1999). Effects of adenosine receptor agonists and antagonists on audiogenic seizure-sensible DBA/2 mice. Eur J Pharmacol 371: $137-145$.

Dragunow M, Goddard GV (1984). Adenosine modulation of amygdale kindling. Exp Neurol 84: 654-665.

Dunwiddie TV (1980). Endogenously released adenosine regulates excitability in the in vitro hippocampus. Epilepsia 21: 541-548.

During MJ, Spencer DD (1992). Adenosine: a potential mediator of seizure arrest and postictal refractoriness. Ann Neurol 32: 618-624.

Fattaccini CM, Bolanos-Jimenez F, Gozlan H, Hamon M (1990). Tianeptine stimulates uptake of 5-hydroxytryptamine in vivo in the rat brain. Neuropharmacology 29: 1-8.

Fredholm BB (1995). Adenosine, adenosine receptors and the actions of caffeine. Pharmacol Toxicol 76: 93-101.

Fredholm BB, Ijzerman AP, Jacobson KA, Klotz KN, Linden J (2001). International Union of Pharmacology. XXV. Nomenclature and classification of adenosine receptors. Pharmacol Rev 53: 527-552.

Hollister LE (1978). Treatment of depression with drugs. Ann Int Med 89: 78-84.
Kaputlu I, Uzbay IT (1997). L-NAME inhibits pentylenetetrazole and strychnine-induced seizures in mice. Brain Res 753: 98-101.

Kato G, Weitsch AF (1988). Neurochemical profile of tianeptine, a new antidepressant drug. Clin Neuropharmacol 11(Suppl 2): S43-S50.

Maitre M, Ciesielski L, Lehman A, Kempf A, Mandel P (1974). Protective effect of adenosine and nicotinamide against audiogenic seizures. Biochem Pharmacol 23: 2807-2816.

Malhotra J, Gupta YK (1997). Effect of adenosine receptor modulation on pentylenetetrazole-induced seizures in rats. Br J Pharmacol 120: 282-288.

Marangos PJ, Loftus T, Weisner J, Lowe T, Rossie E, Browne CE et al (1990). Adenosinergic modulation of homocysteineinduced seizures in mice. Epilepsia 31: 239-246.

McKim WA (2000). Drugs and Behavior. An Introduction to Behavioral Pharmacology, 4th edn. Printice-Hall, Inc.: New Jersey. p 208.

Mennini T, Mocaer E, Garattini S (1987). Tianeptine, a selective enhancer of serotonin uptake in rat brain. Naunyn-Schmi Arch Pharmacol 336: 478-482.

Pagonopoulou O, Angelatau F, Kostopoulos G (1993). Effect of pentylenetetrazol-induced seizures on A1 adenosine receptor regional density in the mouse brain: a quantitative autoradiographic study. Neuroscience 56: 711-716.

Petersen EN (1991). Selective protection by adenosine receptor agonists against DMCM-induced seizures. Eur J Pharmacol 195: 261-265.

Robertson MM (1985). Depression in patients with epilepsy: an overview and clinical study. In: Trimble MR (ed). The Psychopharmacology of Epilepsy. John Wiley: Chichester. p 65.

Rocher C, Speeding M, Munoz C, Jay TM (2004). Acute stressinduced changes in hippocampal/prefrontal circuits in rats: effects of antidepressants. Cerebral Cortex 14: 224-229.

Sanchez-Mateo CC, Darias V, Albertos LM, Exposito-Orta MA (2003). Psychopharmacological effects of tianeptine analogous hetero[2,1] benzothiazepine derivatives. Arzneimit-Forsch 53: $12-20$.

Schultz V, Lowenstein JM (1978). The purine nucleotide cycle: studies of ammonia production and interconversion of adenine and hypoxantine nucleotides and nucleosides by rat brain in situ. J Biol Chem 253: 1938-1943.

Snyder SH (1981). Adenosine receptors and the actions of methylxanthines. Trends Neurosci 4: 242-244.

Tchekalarova J, Sotiriou E, Georgiev V, Kostopoulos G, Angelatou $F$ (2005). Up-regulation of adenosine A1 receptor binding in pentlenetetrazol kindling in mice: effects of angiotensin IV. Brain Res 1032: 94-103.

Uzbay IT, Cinar MG, Aytemir M, Tuglular I (1999). Analgesic effect of tianeptine in mice. Life Sci 64: 1313-1319.

Uzbay IT, Kayir H, Ceyhan M (2004). Tianeptine inhibits pentylenetetrazole-induced seizures in mice via adenosinergic receptors. Eur Neuropsychopharmacol 14(Suppl 3): S367.

Uzbay IT, Kayir H, Çelik T, Yuksel N (2006). Acute and chronic tianeptine treatments attenuate ethanol withdrawal syndrome in rats. Progr Neuro-Psychopaharmacol Biol Psychiat 30: 478-485.

Watanabe Y, Gould E, Daniels DC, Cameron H, McEwen BS (1992). Tianeptine attenuates stress-induced morphological changes in the hippocampus. Eur J Pharmacol 222: 157-162.

Williams M (1990). Purine nucleosides and nucleotides as central nervous system modulators. Adenosine as the prototypic paracrine neuroactive substance. Ann NY Acad Sci 603: 93-107.

Winn HR, Welsh JE, Rubio R, Berne RM (1980). Changes in brain adenosine during bicuculline-induced seizures in rats. Circulation Res 47: 568-577. 